\title{
Estimating urban flood risk - uncertainty in design criteria
}

\author{
M. Newby, S. W. Franks, and C. J. White \\ School of Engineering and ICT, University of Tasmania, Hobart, Australia \\ Correspondence to: S. W. Franks (stewart.franks@utas.edu.au)
}

Received: 17 March 2015 - Accepted: 17 March 2015 - Published: 11 June 2015

\begin{abstract}
The design of urban stormwater infrastructure is generally performed assuming that climate is static. For engineering practitioners, stormwater infrastructure is designed using a peak flow method, such as the Rational Method as outlined in the Australian Rainfall and Runoff (AR\&R) guidelines and estimates of design rainfall intensities. Changes to Australian rainfall intensity design criteria have been made through updated releases of the AR\&R77, AR\&R87 and the recent 2013 AR\&R Intensity Frequency Distributions (IFDs). The primary focus of this study is to compare the three IFD sets from 51 locations Australia wide. Since the release of the AR\&R77 IFDs, the duration and number of locations for rainfall data has increased and techniques for data analysis have changed. Updated terminology coinciding with the 2013 IFD release has also resulted in a practical change to the design rainfall. For example, infrastructure that is designed for a 1:5 year ARI correlates with an $18.13 \%$ AEP, however for practical purposes, hydraulic guidelines have been updated with the more intuitive $20 \%$ AEP. The evaluation of design rainfall variation across Australia has indicated that the changes are dependent upon location, recurrence interval and rainfall duration. The changes to design rainfall IFDs are due to the application of differing data analysis techniques, the length and number of data sets and the change in terminology from ARI to AEP. Such changes mean that developed infrastructure has been designed to a range of different design criteria indicating the likely inadequacy of earlier developments to the current estimates of flood risk. In many cases, the under-design of infrastructure is greater than the expected impact of increased rainfall intensity under climate change scenarios.
\end{abstract}

\section{Introduction}

The design of urban stormwater infrastructure is generally performed under the assumption that climate is static. For engineering practitioners, stormwater infrastructure is conventionally designed using a peak flow method (Chowdhury and Beecham, 2011), such as the Rational Method as outlined in the Australian Rainfall and Runoff (AR\&R). Changes to Australian rainfall intensity design criteria have been made by updated releases of AR\&R77 (The Institution of Engineers, 1977), AR\&R87 (The Institution of Engineers, 1987) and the recent 2013 AR\&R Intensity Frequency Distributions (IFDs) (Australian Rainfall and Runoff, 2013). A primary focus of this study is to compare the three IFD sets from 51 locations Australia wide. These changes, coupled with differing methods in which the Rational Method is undertaken, result in differing design peak flows. These methods and re- sulting peak flows will be analysed as part of this investigation.

As climate change is not considered by the IFD releases, these changes can be attributed to alternate methods of data interpretation and increases in the duration in which the data was collected. However, with the consideration of climate change and variability, rainfall characteristics may not remain constant and result in further changes to the rainfall intensity frequency distributions. Due to the uncertainty surrounding the magnitude of the impacts of climate change, adapting stormwater strategies and infrastructure to accommodate the differing stormwater flows can prove troublesome for stormwater practitioners. Consideration of these inconsistences indicates that stormwater infrastructure will need to function under differing rainfall intensities to those recommended during the design of the infrastructure (Pyke et al., 
2011). In this study, IFDs have been analysed throughout 51 locations within Australia to establish the change in design rainfall for each site.

The Bureau of Meteorology is Australia's national climate and water agency providing observational, meteorological and hydrological services by researching science and environment related issues. As the Bureau of Meteorology acts under the authority of the Meteorological Act 1955 and the Water Act 2007, it is widely recognised as providing industry standard data and thus suitable for this study.

Historical rainfall data interpretation and methods for peak flow estimation are well documented in AR\&R, which provides the industry standard in which rainfall intensities and subsequent peak flow estimations are calculated, hence the AR\&R publications are used frequently throughout this study. Whilst there exists other methods to determine the rainfall intensities, given that AR\&R is Australian industry standard, these methods are explored.

The rainfall intensities as set by AR\&R77, AR\&R87 and the current AR\&R revision are calculated for each of the 51 sites throughout Australia. It is important to note that although AR\&R have provided the industry standard since 1958, the rainfall data collection sites have increased both in duration and number. The method in which the data is interpreted has also changed, resulting in differing design rainfall intensities.

\section{Methodology}

The design of stormwater infrastructure is conventionally designed using a peak flow method, such as the Rational Method as outlined in the Australian Rainfall and Runoff (Chowdhury and Beecham, 2011). The release of a new AR\&R guideline to flood estimation (due in 2015) will introduce new techniques and terminology regarding flood estimation. In order to complete a sensitivity study on a small urban sub-catchment, it is important to understand the subtle differences in the differing terminologies.

Average Recurrence Interval (ARI), Annual Exceedance Probability (AEP) and Exceedances per Year (EY) are all measures of rainfall event occurrence used in the upcoming Australian Rainfall and Runoff guideline for design flood estimation (Bureau of Meteorology, 2013a). Applying the following equations produce the conversions as displayed in Table 1:

$\operatorname{AEP}(\%)=(1-\exp (-1 / \mathrm{ARI})) \cdot 100$

$\operatorname{AEP}(\operatorname{lin} X)=100 / \operatorname{AEP}(\%)$

$\mathrm{EY}=1 / \mathrm{ARI}$

A move towards the use of the term AEP rather than ARI can be attributed to the ease with which each term can be understood. The term ARI has caused some confusion in various forms of government and for general public that interpret the time of recurrence as a regular interval i.e. if Launceston
Table 1. ARI, AEP and EY conversions.

\begin{tabular}{rrrr}
\hline EY & AEP $(\%)$ & AEP $(1$ in $X)$ & ARI \\
\hline 6 & 99.75 & 1.002 & 0.17 \\
4 & 98.17 & 1.02 & 0.25 \\
3 & 95.02 & 1.05 & 0.33 \\
2 & 86.47 & 1.16 & 0.50 \\
1 & 63.21 & 1.58 & 1.00 \\
0.69 & $50.00 *$ & 2.00 & 1.44 \\
0.5 & 39.35 & 2.52 & 2.00 \\
0.22 & $20.00 *$ & 5 & 4.48 \\
0.2 & 18.13 & 5.52 & 5.00 \\
0.11 & 10.00 & 10 & 9.49 \\
0.05 & 5.00 & 20 & 19.5 \\
0.02 & 2.00 & 50 & 49.5 \\
0.01 & 1.00 & 100 & 100 \\
0.005 & 0.50 & 100 & 200 \\
0.002 & 0.20 & 500 & 500 \\
0.001 & 0.10 & 1000 & 1000 \\
0.0005 & 0.05 & 2000 & 2000 \\
0.0002 & 0.02 & 5000 & 5000 \\
\hline * It should be noted that for the 20\% and the 50\% AEP the \\
usual conversion to EY or ARI as the inverse of AEP does \\
not apply; the corresponding correct EY and ARI values are \\
shown in the table. & \multicolumn{3}{|c}{}
\end{tabular}

were to experience a 1:5 year ARI today, another such incident would not occur for five years. Assigning a probability to each rainfall event has proven more effective to convey the similar information (Bureau of Meteorology, 2013b).

The change from ARI to AEP has caused a slight change to the design rainfall regarding the level of service provided by councils. For example, infrastructure that is designed for a 1:5 year ARI correlates with an $18.13 \%$ AEP (see Table 1), practically however hydraulic guidelines are updated with the more intuitive $20 \%$ AEP. This results in a small change to rainfall intensities.

\section{IFD estimation}

The AR\&R77 IFDs were produced by the Bureau of Meteorology through the analysis of 4000 station-years worth of data from 480 pluviograph stations. The analysis was undertaken based on the following assumptions:

- For a given duration, the largest rainfall recorded each year is part of a statistically independent series.

- For durations between 6 min and $72 \mathrm{~h}$ each series has a log-normal distribution.

- The period for which observations are available at each pluviograph site is deemed representative of long-term conditions at that site.

- There is no climatic trend. 


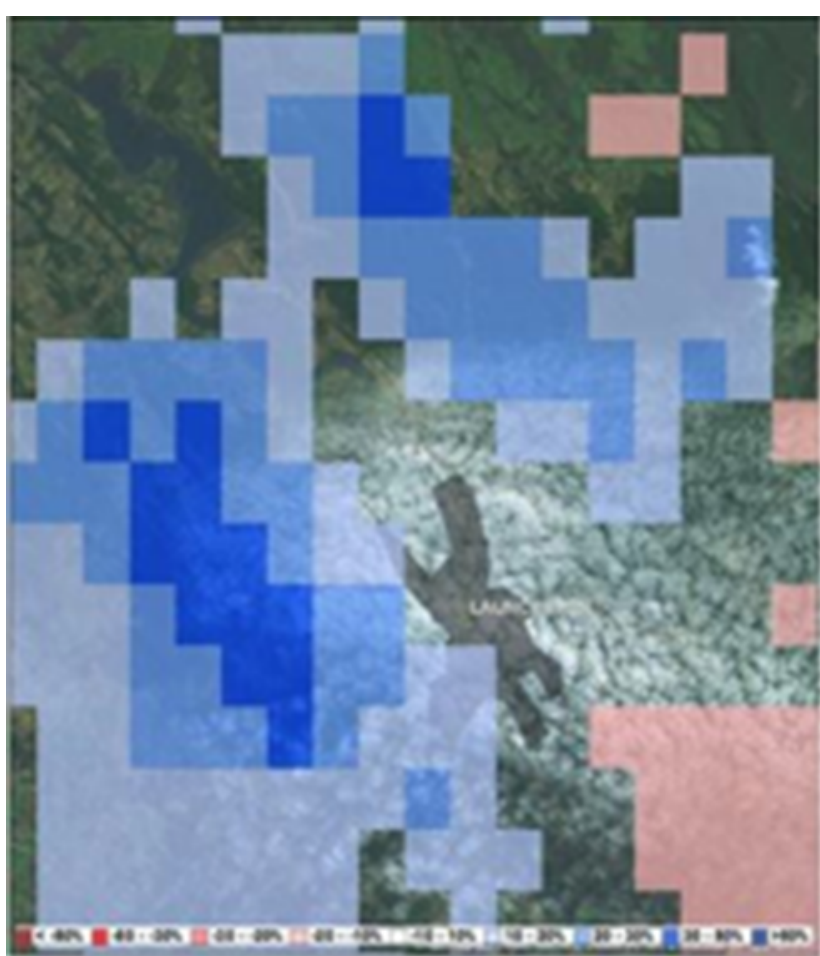

Figure 1. $72 \mathrm{~h}, 50 \%$ AEP comparison mapping.

Each rainfall IFD can be represented by a polynomial equation of the form:

$$
\begin{aligned}
\ln (I) & =a+b(\text { Int })+c(\text { Int })^{2}+d(\text { Int })^{3}+e(\text { Int })^{4} \\
& +f(\text { Int })^{5}+g(\text { Int })^{6}
\end{aligned}
$$

where: Int $=$ The natural logarithm of the storm duration (hours), $I=$ Rainfall intensity, and where coefficients ( $a, b$, $c, d, e, f, g)$ are derived from a polynominal regession and are provided by Australian Rainfall and Runoff (1977).

Updated IFD relationships were re-calculated prior to the release of the publication of AR\&R87. The IFD relationships were determined by analysing all rainfall data collected until 1983 from across Australia. The data collected from each station was deemed representative of long-term conditions and that climatic trends had little effect on intensities. A further update has been provided since the release of the AR\&R87 IFDs. In the case of this most recent update, the duration and number of locations for data collection has increased and new techniques for data analysis have been developed (Australian Rainfall and Runoff, 2013). Table 2 provides a summary of the differing methodologies used to produce AR\&R87 and the new IFDs (Green, 2012). The key difference other than the quantity of data is the use of the Generalised Extreme Value distribution rather than the Log-Pearson III distribution in fitting to the pluviometer data.

The new IFDs are available based on the updated data. However, it is important to note that a complete database of the IFDs will not be finished until 2015. A joint ven-

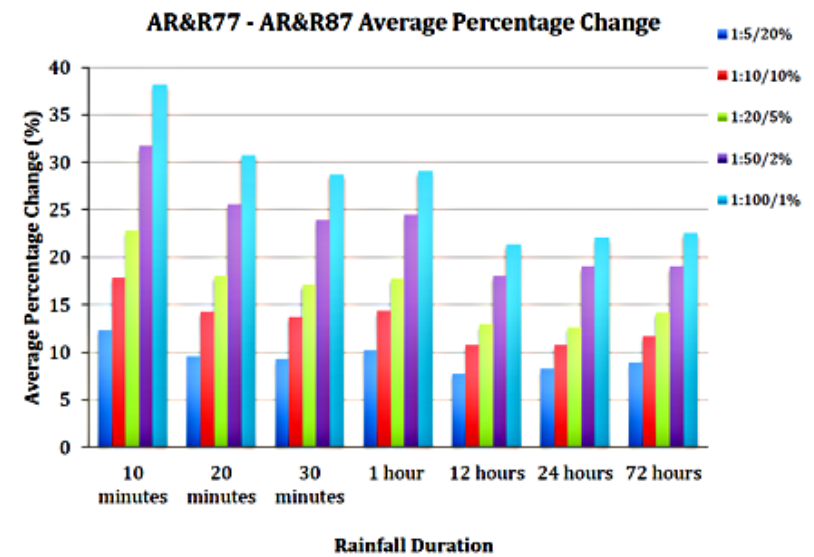

Figure 2. Average percentage change in rainfall intensities between AR\&R77 and AR\&R87.

ture undertaken by the Bureau of Meteorology and the Commonwealth Scientific and Industrial Research Organisation (CSIRO), in conjunction with the University of Adelaide and University of New South Wales (UNSW) aim to deliver a complete updated IFD reference by 2015 . The primary objective of this study will be to "provide interim advice to practitioners on how possible changes in the magnitude and uncertainty of rainfall IFD under anthropogenic climate change can be incorporated into design and planning" (Australian Rainfall and Runoff, 2013).

The differing methodologies and rainfall data sets have resulted in numerical changes to IFDs. The Bureau of Meteorology has generated comparison mapping between the new 2013 and AR\&R87 IFDs for Australian state capitals and upon request, the Bureau of Meteorology also produced similar comparison mapping for Launceston. This mapping outlines the percentage differences between the new IFDs and the AR\&R87 IFDs for a range of AEPs. An example of such mapping is displayed in Fig. 1 which displays the 72 h, $50 \%$ AEP Comparison Mapping.

Figure 2 displays the average percentage change calculated for all 51 sites throughout Australia for the comparison made between the AR\&R77 and AR\&R87 IFDs. The figure displays an overall percentage change that generally decreases as duration increases for a particular recurrence interval (ARI/AEP). The figure also displays an overall percentage change that increases as the recurrence interval increases (ARI/AEP). These results indicate that changes to IFDs are very much dependant on duration and recurrence interval.

Figure 3 displays the average percentage change calculated for all 51 sites throughout Australia for the comparison made between the AR\&R87 and the new 2013 IFDs. The figure displays that the average percentage increases are at a minimum between the 1 and $24 \mathrm{~h}$ durations and increase as the rainfall durations tend towards the $10 \mathrm{~min}$ and $72 \mathrm{~h}$ durations. Figure 4 displays the average percentage change calculated for all 51 sites throughout Australia for the com- 
Table 2. Differing methodologies for AR\&R87 and the new 2013 IFDs.

\begin{tabular}{lll}
\hline Method & New IFDs & AR\&R87 IFDs \\
\hline $\begin{array}{l}\text { Number of rainfall } \\
\text { stations }\end{array}$ & $\begin{array}{l}\text { Daily read }-8074 \\
\text { Continuous }-2280\end{array}$ & $\begin{array}{l}\text { Daily read }-7500 \\
\text { Continuous }-600\end{array}$ \\
\hline Period of record & All available records up to 2012 & $\begin{array}{l}\text { All available records up to } \\
\text { 1983 }\end{array}$ \\
\hline $\begin{array}{l}\text { Length of record used in } \\
\text { analyses }\end{array}$ & $\begin{array}{l}\text { Daily read }>\text { 30 years } \\
\text { Continuous }>8 \text { years }\end{array}$ & $\begin{array}{l}\text { Daily read }>\text { 30 years } \\
\text { Continuous }>\text { 6 years }\end{array}$ \\
\hline Extreme value series & Annual Maximum Series (AMS) & Annual Maximum Series (AMS) \\
\hline Frequency analysis & $\begin{array}{l}\text { Generalised Extreme Value } \\
\text { (GEV) distribution fitted using }\end{array}$ & $\begin{array}{l}\text { Log-Pearson Type III } \\
\text { (LPIII) distribution fitted } \\
\text { using method of moments }\end{array}$ \\
\hline
\end{tabular}

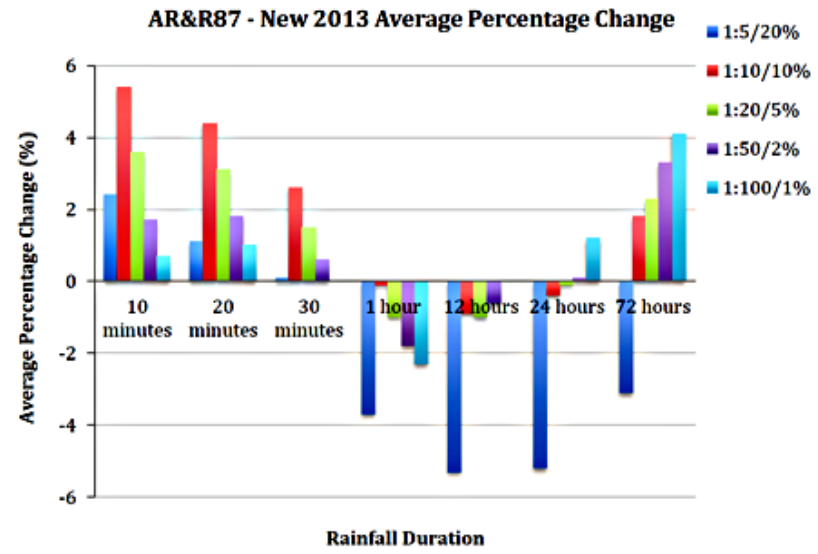

Figure 3. Average percentage change in rainfall intensities between AR\&R87 and 2013 update.

parison made between the AR\&R87 and the new 2013 IFDs. The figure displays an overall percentage change that generally decreases as the duration increases from a ten-minute duration towards $24 \mathrm{~h}$, the average percentage change once again increases as the duration increases towards $72 \mathrm{~h}$.

\section{Case study - Rennie Court, Tasmania}

To illustrate the impact of changed IFD design estimates as well as changes to the calculation of the peak flows through the rational method, a brief case study is demonstrated. According to Launceston City Council records, the pipe work down stream from Rennie Court was built in 1982 and therefore subject to differing IFDs and Rational Method calculation methodologies. The following flow estimates were produced adhering to standard techniques of flood estimation for Tasmania as set in AR\&R77 and AR\&R87.

Table 3 displays the results of the Rational Method procedures calculated for the Rennie Court catchment. As can

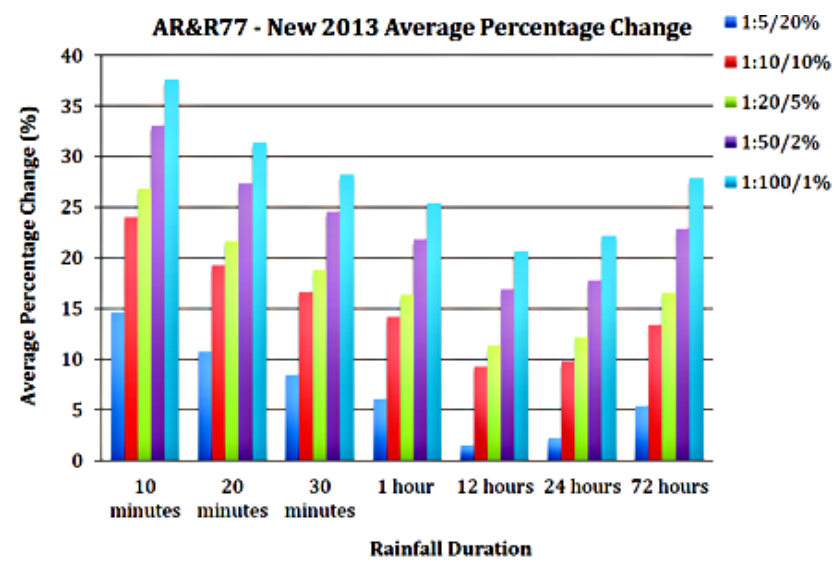

Figure 4. Average percentage change in rainfall intensities between AR\&R77 and 2013 update.

Table 3. Changes in estimated probable flows compared to AR\&R77.

\begin{tabular}{lrr}
\hline IFD & ARI/AEP & $\begin{array}{r}\text { Probable } \\
\text { Flow Change }\end{array}$ \\
\hline AR\&R87 & $1: 5$ ARI/20\% AEP & $14.7 \%$ \\
& $1: 100$ ARI/1 \% AEP & $80.4 \%$ \\
\hline New 2013 & $1: 5$ ARI/20\% AEP & $12.1 \%$ \\
& $1: 100$ ARI/1\% AEP & $81.3 \%$ \\
\hline
\end{tabular}

be seen, the estimated flows for the $20 \%$ AEP indicate that the infrastructure is likely to be $>10 \%$ underdesigned. More significantly, the estimated $1 \%$ AEP flows indicate an $80 \%$ increase in estimated flows. These increases are primarily due to the major change in design rainfalls due to the updating of the AR\&R77 IFD curves for the revised AR\&R87 curves. 


\section{Conclusions}

The primary focus of this study has been to compare the three IFD sets from 51 locations Australia wide. Since the release of the AR\&R77 IFDs, the duration and number of locations for rainfall data has increased and techniques for data analysis have changed. Updated terminology coinciding with the 2013 IFD release has also resulted in a practical change to the design rainfall. For example, infrastructure that is designed for a $1: 5$ year ARI correlates with an $18.13 \%$ AEP, practically however hydraulic guidelines are updated with the more intuitive $20 \%$ AEP. This assessment of design rainfall variation across Australia has indicated that the changes are dependent upon location, recurrence interval and rainfall duration. The changes to design rainfall IFDs are due to the application of differing data analysis techniques, the length and number of data sets and the change in terminology from ARI to AEP. Such changes mean that developed infrastructure has been designed to a range of different design criteria indicating the likely inadequacy of earlier developments to the current estimates of flood risk. In many cases, the underdesign of infrastructure is greater than the expected impact of increased rainfall intensity under climate change scenarios.

A particular area of interest for local councils regarding climate change impacts is the changing magnitude and frequency of rainfall. The current AR\&R revision (due for completion in 2015) will provide more definitive advice for engineering and planning practitioners regarding this issue. In the interim however, policy makers and hydraulic practitioners need to assess how a variable climate may impact future rainfalls and likely consequences of increased storm water runoff on current infrastructure. Decisions made today need to occur in a way which ensures that the outcomes of those decisions are robust enough to cope with, or adapt to, changing climatic conditions in the future (NAMS and IPWEA, 2011; Green and Johnson, 2012).

Statewide, Tasmania's annual rainfall is not projected to vary markedly by the year 2100 , however the frequency distribution of the rainfall is expected to change. Generally, Launceston can expect longer dry periods interspersed with heavier more intense rainfalls with projected rainfall intensity increases range from 0 to $35 \%$ across the range of ARI events. This projection, coupled with the results of the IFD comparison and the exceedances study, indicate the range of uncertainty in design rainfall intensities and subsequent runoff.
Acknowledgements. The authors thank Launceston City Council for their support in this study.

\section{References}

Australian Rainfall and Runoff: Project 1: Development of Intensity Frequency Duration Information across Australia, available at: http://www.arr.org.au/revision-projects/project-list/ project-1/, 2013.

Bureau of Meteorology: Glossary: ARI and AEP, available at: http: //www.bom.gov.au/water/designRainfalls/ifd/glossary.shtml, 2013a.

Bureau of Meteorology: Frequently Asked Questions: New AR\&R probability terminology, available at: http:/www.bom.gov.au/ water/designRainfalls/ifd/ifd-faq.shtml\#sec1q6, 2013 b.

Chowdhury, R. and Beecham, S.: Stormwater Drainage Design under Climate Change and Variability Conditions, in: Proceedings of the 34th World Congress of the International Association for the Hydro- Environment Research and Engineering: 33rd Hydrology and Water Resources Symposium and 10th Conference on Hydraulics in Water Engineering, edited by: Valentine, E. M., Apelt, C. J., Ball, J., Chanson, H., Cox, R., Ettema, R., Kuczera, G., Lambert, M., Melville, B. W., and Sargison, J. E., Barton, Australia, 734-741, 1492, 2011.

Green, J.: The Revised Intensity-Frequency-Duration (IFD) Design Rainfall Estimates for Australia - An Overview, in: Proceedings of the 34th Hydrology and Water Resources Symposium, 19-22 November 2012, Sydney, Australia, 2012.

Green, J. and Johnson, F.: Incorporation of Climate Change in Intensity-Frequency-Duration (IFD) Design Rainfall Estimates, in: Proceedings of the 2nd Practical Responses to Climate Change Conference, "Water and Climate: Policy Implementation Challenges”, 1-3 May 2012, Canberra, Australia, 2012.

NAMS and IPWEA: International Infrastructure Management Manual v.4.0, NAMS Limited, Wellington, New Zealand, 2011.

Pyke, C., Warren, M., Johnson, T., Lagro, J., Scharfenberg, J., Groth, P., Freed, R., Schroeer, W., and Main, E.: Assessment of low impact development for managing stormwater with changing precipitation due to climate change, Landsc. Urban Plann., 103, 166-173, 2011.

The Institution of Engineers: Australian Rainfall and Runoff: Flood Analysis and Design, Editor and Chairman of Editorial Panel A. Pattison, Revised Edition 1977 (Reprinted Edition 1979, 1981, 1983), Barton ACT, 1977.

The Institution of Engineers: Australian Rainfall and Runoff: A Guide to Flood Estimation, Vol. 1, edited by: Pilgrim, D. H., Revised Edition 1987 (Reprinted Edition 1998), Barton ACT, 1987. 